\title{
ELECTROPHORETIC COMPONENTS OF THE HEMOGLOBIN OF RED CELL MEMBRANES *
}

\author{
By FREDERICK A. KLIPSTEIN † AND HELEN M. RANNEY
}

\author{
(From the Department of Medicine, College of Physicians and Surgeons of Columbia Uni- \\ versity, and the Presbyterian Hospital, New York, N. Y.)
}

(Submitted for publication June 23, 1960; accepted August 11, 1960)

Erythrocyte membranes prepared by repeated washings with water have been shown by Anderson and Turner (1) to contain relatively constant amounts of hemoglobin. The hemoglobin of lyophilized erythrocyte membranes represented about 3 per cent of the total erythrocyte hemoglobin and between 49 and 57 per cent of dry weight of the membranes (1). No differences between the membrane hemoglobin and the watersoluble hemoglobin obtained by the lysis of the whole erythrocytes have been noted in spectrophotometric studies when both were converted to cyanmethemoglobin (2). However, if a part of the hemoglobin is indeed bound to the membrane it might exhibit other properties distinguishing it from the remainder of the hemoglobin of the red cell.

The present studies were designed to examine further whether the hemoglobin attached to membranes differs from the hemoglobin obtained in watery solution after lysis of erythrocytes with water and toluene by the method of Drabkin (3), or from the water-soluble hemoglobin obtained by lysis of erythrocytes with 12 volumes of water.

\section{MATERIALS AND METHODS}

Blood samples were taken in acid citrate dextrose (ACD) solution and the erythrocytes were washed 4 times with normal saline. An aliquot of washed erythrocytes was lysed with water and toluene by the method of Drabkin (3), and a clear solution of hemoglobin was obtained after centrifugation at $15,000 \times \mathrm{G}$ for $40 \mathrm{~min}-$ utes. This hemoglobin preparation, designated "hemolysate hemoglobin," was converted to cyanmethemoglobin or carbonmonoxyhemoglobin for analyses. Comparative electrophoretic studies of hemolysate hemoglobin prepared by lysis with water and toluene and of watersoluble hemoglobin obtained by lysis of the washed eryth-

* This investigation was supported by Grant A-1017 from the National Institute of Arthritis and Metabolic Diseases, Bethesda, Md.

+ Public Health Service Trainee of the National Institute of Arthritis and Metabolic Diseases, National Institutes of Health. rocytes with 12 volumes of cold water revealed no significant differences in the relative amounts of the major and minor hemoglobin components. Therefore, either preparation was utilized for comparison with the membrane pigment.

After lysis of the erythrocytes with 12 volumes of cold water, washings of the membranes with cold water were continued until no color could be observed in the water; the red cell membranes were still distinctly reddish in color. To remove the hemoglobin from the erythrocyte membranes two different procedures were employed. In the first procedure, cyanmethemoglobin was prepared by the addition of 2 to 3 volumes of 50 per cent urea in Drabkin's diluent ${ }^{1}$ (4) to the wet membranes. The mixture was agitated for 5 to 10 minutes and centrifuged at $15,000 \times \mathrm{G}$ for 40 minutes. After centrifugation, the reddish precipitate of stroma was discarded. The clear supernatant solution of cyanmethemoglobin was dialyzed with stirring against at least 500 volumes of cold distilled water, with several changes, and centrifuged again before analyses were carried out. Cyanmethemoglobin concentrations of 0.2 to $0.3 \mathrm{~g}$ per $100 \mathrm{ml}$ were obtained by this method, and further concentration to $1 \mathrm{~g}$ per 100 $\mathrm{ml}$ could be achieved in a Toribara ultrafiltration apparatus. When membrane hemoglobin prepared by this procedure was compared with hemolysate hemoglobin, the hemolysate hemoglobin was diluted with urea-Drabkin's diluent and dialyzed in the same manner. In a second procedure for the preparation of membrane hemoglobin the carbonmonoxy pigment was obtained. The lysed erythrocytes were exposed to carbon monoxide and the wet membranes collected by centrifugation. The packed wet membranes were then homogenized in an equal volume of cold veronal buffer $(\mathrm{pH} 8.6$, ionic strength 0.04) for 2 to 4 minutes in a multi-mixer (Lourdes). The mixture was centrifuged and the clear supernatant solution of pigment was again exposed to carbon monoxide. Dialysis was omitted; water-soluble carbonmonoxyhemoglobin was compared electrophoretically with the preparation of membrane hemoglobin.

Electrophoretic analyses of the hemoglobin preparations were carried out by the starch granule technique of Kunkel, Ceppellini, Müller-Eberhard and Wolf (5). Hemolysate or water-soluble and membrane hemoglobin preparations of approximately the same concentration

\footnotetext{
${ }_{1}^{1}$ Drabkin's diluent solution consists of $1.0 \mathrm{~g} \mathrm{NaHCO}_{3}$, $50 \mathrm{mg} \mathrm{KCN}, 200 \mathrm{mg} \mathrm{K}_{3} \mathrm{Fe}(\mathrm{CN})_{6}$, and distilled water to $1 \mathrm{~L}$.
} 
were run simultaneously on the same starch block, and the concentration of pigment in eluates was determined with a Beckman DU spectrophotometer. Duplicate or triplicate analyses were carried out for each preparation. Electrophoretic separations were also carried out on starch gels by the method of Smithies (6) at $4^{\circ} \mathrm{C}$, using $180 \mathrm{v}$ for 16 hours. The gels were stained with both benzidine and amido-black.

\section{RESULTS}

Human subjects without known hemoglobin abnormalities. Hemolysate or water-soluble hemoglobin and membrane hemoglobin were prepared from the erythrocytes of seven normal subjects and analyzed electrophoretically on starch granules (5) and starch gels (6). Normal human hemoglobin contains at least three electrophoretically distinct components : the slow moving minor component, hemoglobin $\mathrm{A}_{2}$, which includes 1.5 to 3.5 per cent of the total pigment; the rapid minor component, hemoglobin $\mathrm{A}_{3}$, which may comprise approximately 4 to 12 per cent of the total; and the main component, hemoglobin $A_{1}$ (5, $7)$. All three of these components were demonstrated by both starch block and starch gel electrophoresis of normal membrane hemoglobin prepared by either procedure. Concentrations of membrane hemoglobin of $0.2 \mathrm{~g}$ per $100 \mathrm{ml}$ were sufficient to demonstrate both minor components on starch gels. However, for quantification of minor components on starch granules, concentrations of membrane hemoglobin of at least 0.5 to 1 g per $100 \mathrm{ml}$ were desirable. When membrane hemoglobin was prepared by mechanical homogenizing in veronal buffer, carbonmonoxyhemo-

TABLE I

Per cent of electrophoretically slow $\left(A_{2}\right)$ hemoglobin in water-soluble and membrane hemoglobin

\begin{tabular}{lcc}
\hline & \multicolumn{2}{c}{$\begin{array}{c}\text { Per cent } \mathrm{A}_{2} \text { hemo- } \\
\text { globin in }\end{array}$} \\
\cline { 2 - 3 } $\begin{array}{c}\text { Normal } \\
\text { subjects }\end{array}$ & $\begin{array}{c}\text { Water-soluble } \\
\text { hemoglobin* }\end{array}$ & $\begin{array}{c}\text { Membrane } \\
\text { hemoglobin† }\end{array}$ \\
\hline H.R. & 2.7 & 7.6 \\
G.O. & 1.7 & 7.0 \\
J.P. & 1.2 & 4.1 \\
M.R. & 1.8 & 6.6 \\
L.D. & 1.5 & 5.1 \\
M.M. & 2.2 & 10.3 \\
P.M. & 2.0 & 6.9 \\
Median & 1.8 & 6.9 \\
\hline
\end{tabular}

* Carbonmonoxyhemoglobin prepared by lysis of erythrocytes with 12 volumes of water.

† Carbonmonoxyhemoglobin prepared by mechanical homogenizing of membranes in veronal buffer.
TABLE II

Per centiof abnormal major hemoglobin component in hemolysate (or water-soluble) hemoglobin and in membrane hemoglobin

\begin{tabular}{|c|c|c|c|}
\hline \multirow[b]{2}{*}{ Subjects } & \multirow[b]{2}{*}{ Hemoglobins } & \multicolumn{2}{|c|}{$\begin{array}{c}\text { Percentage of designated } \\
\text { hemoglobin in }\end{array}$} \\
\hline & & $\begin{array}{l}\text { Hemolysate } \\
\text { hemoglobin }\end{array}$ & $\begin{array}{l}\text { Membrane } \\
\text { hemoglobin }\end{array}$ \\
\hline $\begin{array}{l}\text { E.R. } \\
\text { A.S. } \\
\text { E.G. } \\
\text { P.W. } \\
\text { S.G. } \\
\text { E.W. } \\
\text { M.M. } \\
\text { M.A. } \\
\text { C.H. } \\
\text { A.P. } \\
\text { Ca.L. } \\
\text { Ce.L. } \\
\text { G.S. }\end{array}$ & $\begin{array}{l}\mathrm{S}+\mathrm{A} \\
\mathrm{S}+\mathrm{A} \\
\mathrm{S}+\mathrm{A} \\
\mathrm{S}+\mathrm{A} \\
\mathrm{S}+\mathrm{A} \\
\mathrm{S}+\mathrm{A} \\
\mathrm{S}+\mathrm{A} \\
\mathrm{S}+\mathrm{A} \\
\mathrm{S}+\mathrm{A} \\
\mathrm{S}+\mathrm{A} \\
\mathrm{S}+\mathrm{A} \\
\mathrm{S}+\mathrm{A} \\
\mathrm{S}+\mathrm{A} \\
\mathrm{S}+\mathrm{A}\end{array}$ & $\begin{array}{l}40 \text { (S)* }^{*} \\
41(\mathrm{~S})^{*} \\
39(\mathrm{~S})^{*} \\
42(\mathrm{~S})^{*} \\
38(\mathrm{~S})^{*} \\
31(\mathrm{~S})^{*} \\
39(\mathrm{~S})^{*} \\
38(\mathrm{~S})^{*} \\
39(\mathrm{~S})^{*} \\
26(\mathrm{~S})^{*} \\
33(\mathrm{~S})^{+} \\
44(\mathrm{~S})^{*} \\
42(\mathrm{~S}) \ddagger \\
33(\mathrm{~S}) \ddagger\end{array}$ & 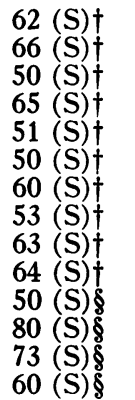 \\
\hline \multicolumn{2}{|c|}{$\begin{array}{l}\text { Average } \mathrm{S}+\mathrm{A} \\
\text { Range } \mathrm{S}+\mathrm{A}\end{array}$} & $\begin{array}{l}37.5(\mathrm{~S}) \\
26-44(\mathrm{~S})\end{array}$ & $\begin{array}{l}60.5(\mathrm{~S}) \\
50-80(\mathrm{~S})\end{array}$ \\
\hline $\begin{array}{l}\text { C.S. } \\
\text { T.M. } \\
\text { L.I. }\end{array}$ & $\begin{array}{l}S+C \\
S+C \\
S+C\end{array}$ & $\begin{array}{l}45 \text { (C) } \ddagger \\
48 \text { (C) }) \\
45 \text { (C) } \ddagger\end{array}$ & $\begin{array}{l}72 \text { (C) } \$ \\
80 \text { (C) } \$ \\
75 \text { (C) } \$\end{array}$ \\
\hline \multicolumn{2}{|c|}{ Average $S+C$} & $46(C)$ & $72(\mathrm{C})$ \\
\hline $\begin{array}{l}\text { A.K. } \\
\text { R.I. }\end{array}$ & $\begin{array}{l}\mathrm{C}+\mathrm{A} \\
\mathrm{C}+\mathrm{A}\end{array}$ & $\begin{array}{l}34(\mathrm{C}) \ddagger \\
21(\mathrm{C}) \ddagger\end{array}$ & $\begin{array}{l}86(\mathrm{C}) \S \\
50(\mathrm{C}) \S\end{array}$ \\
\hline \multicolumn{2}{|c|}{ Average $\mathrm{C}+\mathrm{A}$} & $28(\mathrm{C})$ & $68(C)$ \\
\hline
\end{tabular}

* Hemolysate hemoglobin prepared by lysis of erythrocytes with water and toluene.

t Cyanmethemoglobin prepared with urea-Drabkin's diluent.

$\ddagger$ Water-soluble hemoglobin prepared by lysis of erythrocytes with 12 volumes of water.

$\S$ Carbonmonoxyhemoglobin prepared by homogenizing membranes in veronal buffer.

globin concentrations sufficient for quantification on starch granule electrophoresis were achieved. Quantitative estimations (as per cent of total hemoglobin) for the electrophoretically slow $\left(A_{2}\right)$ component of water-soluble and membrane hemoglobin of seven normal subjects are recorded in Table I. Values for hemoglobin $A_{2}$ in water-soluble hemoglobin ranged from 1.2 to 2.7 per cent. These values are within normal range for hemoglobin $\mathrm{A}_{2}$ estimations on hemolysate hemoglobin (5). The electrophoretically slow component of the membrane pigment ranged from 4 to 10 per cent of the total hemoglobin in the membrane. The proportion of electrophoretically slow component in the membrane hemoglobin was therefore approximately three to four times that in the water-soluble pigment of these normal subjects.

Subjects with electrophoretically abnormal hemoglobin. The results of starch granule electro- 


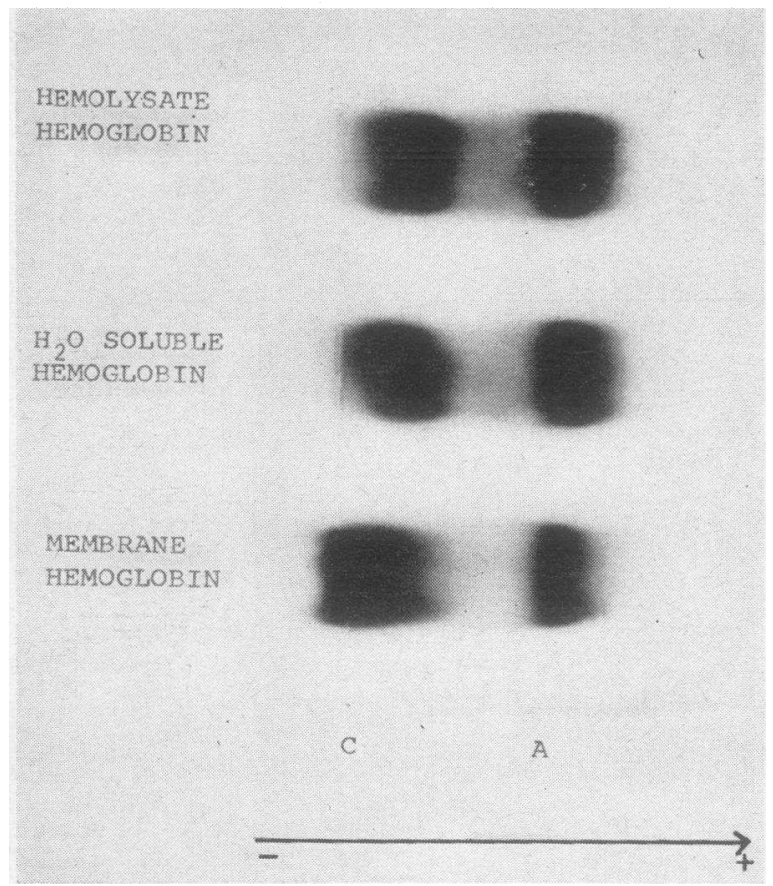

Fig. 1. Starch gel electrophoresis of hemolysate, WATER-SOLUBLE, AND MEMBRANE HEMOGLOBIN FROM A SUbJect With hemoglobin C trait. Concentrations of all preparations were $0.5 \mathrm{~g}$ per $100 \mathrm{ml}$. Electrophoresis in borate buffer at $\mathrm{pH} 8.8$ for 16 hours; benzidine stain. Note the greater proportion of hemoglobin $\mathrm{C}$ in the membrane preparation.

phoretic analyses of hemolysate or water-soluble hemoglobin and of membrane hemoglobin in 18 subjects with heterozygous or compound states for the abnormal hemoglobins are recorded in Table II. In 13 subjects with sickle cell trait, values for hemoglobin $\mathrm{S}$ in the hemolysate or water-soluble hemoglobin ranged from 26 to 44 per cent; these values are similar to those reported by other investigators $(8,9)$. In contrast, the values for hemoglobin $\mathrm{S}$ in membrane hemoglobin ranged from 50 to 80 per cent of the total membrane pigment. Elevated values for hemoglobin $\mathrm{S}$ in membranes were found in both carbonmonoxy and cyanmethemoglobin preparations.

Studies of the erythrocytes of three individuals with sickle cell-hemoglobin $\mathrm{C}$ disease disclosed 45 to 48 per cent hemoglobin $\mathrm{C}$ in the water-soluble pigment and 70 to 75 per cent hemoglobin $C$ in the membrane hemoglobin. In two individuals with hemoglobin $C$ trait, larger proportions ( 50 to 60 per cent) of the abnormal hemoglobin were found in the membranes than in the hemolysate hemoglobin (21 and 34 per cent). Starch gel electro- phoretic analyses of these hemoglobin preparations demonstrated clearly the relative increase in electrophoretically slow components in the membrane pigment (Figure 1).

In individuals with sickle cell trait or hemoglobin $C$ trait, the abnormal hemoglobin was found to be increased in the membrane pigment as compared with the hemolysate hemoglobin, in every case. In the three individuals with sickle cellhemoglobin $\mathrm{C}$ disease, the proportion of the electrophoretically slower hemoglobin $\mathrm{C}$ was found to be increased in the membrane preparations.

Patients with thalassemia minor. Four patients with hematological findings of thalassemia minor, including elevated values of hemoglobin $A_{2}$ in the hemolysate hemoglobin, were studied. The results of starch granule electrophoretic analyses of the water-soluble hemoglobin and of membrane carbonmonoxyhemoglobin are recorded in Table III. An increased proportion of hemoglobin $\mathrm{A}_{2}$ was observed in the membrane hemoglobin as compared with the water-soluble pigment. The average value for water-soluble hemoglobin $A_{2}$ was 5.4 per cent, while hemoglobin $\mathrm{A}_{2}$ accounted for 11 per cent of the membrane pigment.

\section{DISCUSSION}

Kunkel and Wallenius (10) found three electrophoretically distinct components in normal human hemolysate hemoglobin. In the present study, these same three components were found in zone electrophoretic separations of the hemoglobin associated with normal red cell membranes. However, the proportion of the minor basic component, hemoglobin $\mathrm{A}_{2}$, which comprises 1.5 to 3.5 per cent of hemolysate hemoglobin (5), was

TABLE III

Per cent of electrophoretically slow $\left(A_{2}\right)$ hemoglobin in watersoluble and membrane hemoglobin

\begin{tabular}{ccc}
\hline $\begin{array}{c}\text { Patients } \\
\text { with } \\
\text { thalassemia } \\
\text { minor }\end{array}$ & \multicolumn{2}{c}{ Per cent hemoglobin $\mathrm{A}_{2}$ in } \\
\cline { 2 - 3 } $\begin{array}{c}\text { Water-soluble } \\
\text { hemoglobin* }\end{array}$ & $\begin{array}{c}\text { Membrane } \\
\text { hemoglobint }\end{array}$ \\
\hline D.M. & 5.6 & 10.6 \\
B.M. & 4.7 & 11.9 \\
O.N. & 6.1 & 10.2 \\
M.B. & 5.0 & 10.9 \\
Average & 5.4 & 10.9 \\
\hline
\end{tabular}

* Carbonmonoxyhemoglobin prepared by lysis of erythrocytes with 12 volumes of water.

† Carbonmonoxyhemoglobin prepared by homogenizing membranes in veronal buffer. 


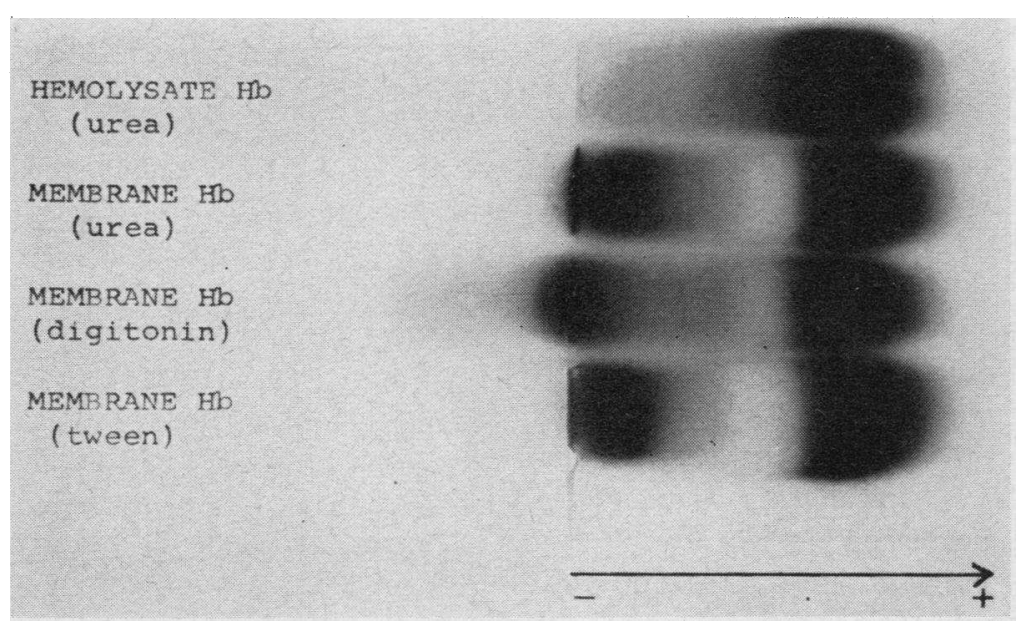

Fig. 2. Starch gel electrophoresis of hemolysate hemoglobin and MEMBRANE HEMOGLOBIN PREPARED WITH VARIOUS AGENTS. Electrophoresis in borate buffer at $\mathrm{pH} 8.8$ for 16 hours. Hemoglobin concentration of all samples $0.3 \mathrm{~g}$ per $100 \mathrm{ml}$; benzidine stain. Note the presence of $\mathrm{A}_{2}$ component in all of the membrane preparations and apparent absence in the hemolysate at this concentration.

found to be increased (median 6.9 per cent) in the membrane pigment of normal subjects.

Comparative electrophoretic studies of membrane and hemolysate hemoglobin of individuals with uncomplicated sickle cell trait or hemoglobin $\mathrm{C}$ trait disclosed increased amounts of the abnormal hemoglobin ( $\mathrm{S}$ or $\mathrm{C}$ ) in the membrane preparations. The measurements of hemoglobin $\mathrm{S}$ or of hemoglobin $\mathrm{C}$ in both the hemolysate and the membrane preparations included hemoglobin $\mathrm{A}_{2}$, but the amount of this minor component did not appear sufficient to account for the large increments of hemoglobin $\mathrm{S}$ or $\mathrm{C}$ observed in the membrane preparations. On three electrophoretic analyses of hemoglobin from individuals with sickle cell trait, sufficiently good separation of hemoglobin $A_{2}$ from hemoglobin $S$ to allow separate quantification of these components was achieved. In these analyses, the average values for hemoglobin $\mathrm{A}_{2}$ and hemoglobin $\mathrm{S}$ in the water-soluble pigment were 1.9 and 35 per cent, respectively; but in the membrane, hemoglobin $\mathrm{A}_{2}$ accounted for as much as 5.3 per cent and hemoglobin $S$ for no less than 68 per cent of the total pigment. Electrophoresis of the membrane hemoglobin of patients with sickle cell-hemoglobin $\mathrm{C}$ disease disclosed a higher proportion of hemoglobin $\mathrm{C}$ than of hemoglobin $\mathrm{S}$ in the membranes.

Appraisal of the validity of the methods employed in this study is necessary for the interpre- tation of the results. The reproducibility of analyses of chemical composition and hemoglobin content of red cell membranes prepared in this manner has been pointed out by Anderson and Turner (2); they also noted that concentrated solutions of urea did not change the spectrophotometric characteristics of cyanmethemoglobin. No new electrophoretic components which would suggest recombination of polypeptide chains (11, 12) was encountered in analyses of the ureatreated hemoglobin, although the electrophoretic mobility of the $\mathrm{S}$ or $\mathrm{C}$ hemoglobin in membrane pigment was at times slightly slower than expected.

Increases in hemoglobin $A_{2}$, hemoglobin $S$ and hemoglobin $\mathrm{C}$ in membrane preparations from normal individuals, those with sickle cell trait, and patients with sickle cell-hemoglobin $\mathrm{C}$ disease, respectively, were observed when urea was omitted and veronal was used to solubilize the membrane pigment. While some foaming was encountered in mechanically homogenizing the membranes in veronal buffer, similar treatment of water-soluble hemoglobin did not alter the expected distribution of electrophoretic components.

In the initial studies, membrane hemoglobin was solubilized in 50 per cent urea in Drabkin's diluent. Two other agents, $4 \times 10^{-4} \mathrm{M}$ digitonin in $0.015 \mathrm{M}$ borate buffer, $\mathrm{pH} 8.9$, and a solution of Tween 20 in normal saline, were also used to 
solubilize the membrane pigment. Membrane hemoglobin prepared with any of the three agents contained a greater proportion of hemoglobin $\mathrm{A}_{2}$ than did hemolysate hemoglobin (Figure 2), although differences in the amount of "trailing" on starch gel electrophoresis were evident in different preparations. The treatment of hemolysate hemoglobin with any of these agents did not appear to increase the proportion of electrophoretically slow minor component.

To study the possibility that the observed increase in the electrophoretically slow hemoglobin components in the membrane pigment was the result of preferential elution of the electrophoretically more rapid components, the following experiments were carried out. Standard membranes were prepared from a subject with sickle cell trait and from a subject with hemoglobin $C$ trait. The first fraction of membrane pigment was then obtained by homogenizing the membranes in veronal buffer; the second and third fractions were obtained by successive additions to the centrifuged reddish stroma of 2 volumes of 50 per cent urea in Drabkin's diluent. The final residue after the second treatment with urea was a very small amount of reddish stroma. Starch gel electrophoresis of the three preparations of membrane pigment of both the $\mathrm{S}+\mathrm{A}$ and the $\mathrm{C}+\mathrm{A}$ erythrocytes revealed relative increases in the amounts of the electrophoretically slow components in all three fractions. The second and third fractions were too dilute for quantification on starch granules but no differences in the relative amounts of electrophoretically slow components of any of the three fractions were apparent on starch gel electrophoretic analyses.

Thus, membrane hemoglobin, prepared by several methods, contained relatively more of the basic components, $\mathrm{A}_{2}, \mathrm{~S}$, or $\mathrm{C}$, than did hemolysate hemoglobin. This increase seemed too regular and large to be an artifact.

Several possible explanations for these findings were suggested.

1) The possibility that the composition of membrane pigment reflected the selection of a certain erythrocyte population should be considered. Allison (13) found that the sickled osmotically resistant erythrocytes of individuals with sickle cell trait contained more sickle hemoglobin than did the osmotically fragile cells. The method of prepa- ration of membranes in the present study might have resulted in the preferential loss of osmotically fragile cells. A selection of the cells containing more sickle (or C) hemoglobin from a heterogeneous population of erythrocytes might contribute to the observed increase in abnormal hemoglobin in the membrane preparations. However, we have been unable to prepare by fractional osmotic lysis (without deoxygenation) any populations of erythrocytes which differ by more than 5 per cent in hemoglobin $S$ content, and no significant increase in hemoglobin $\mathrm{A}_{2}$ has been noted in normal red cells subjected to graded osmotic lysis (5).

2) It might be postulated that membrane hemoglobin contains a hypothetical "membrane-hemoglobin $A_{1}$ complex" with the electrophoretic properties of hemoglobin $\mathrm{A}_{2}, \mathrm{~S}$ or $\mathrm{C}$. The slight alterations in electrophoretic mobility of membrane $\mathrm{A}_{2}, \mathrm{~S}$ and $\mathrm{C}$ might well be related to the presence of non-hemoglobin constituents in the membrane preparations. Direct evidence concerning a "membrane-hemoglobin $A_{1}$ complex" is difficult to obtain. Rabbit hemoglobin contains no minor basic component, and no such component was demonstrable in rabbit membrane pigment. However, different species would be expected to have differences in chemical composition of erythrocyte membranes, and such a complex is a possible explanation of the findings of the present study.

3 ) At present the simplest explanation that can be offered for the observed differences in hemoglobin components is that $\mathrm{A}_{2}, \mathrm{~S}$ and $\mathrm{C}$ are indeed increased in relative amounts in the membranes when the membranes are prepared by the method specified. The fact that the more electropositive hemoglobin component was found to be increased in the membrane pigment suggests that the binding of hemoglobin to the membrane may be related to the hemoglobin charge. Some support for this interpretation may be derived from observations of the composition of membrane pigment in patients with sickle cell-hemoglobin $\mathrm{C}$ disease. While hemoglobin $\mathrm{S}$ accounted for 50 to 80 per cent of the membrane pigment of individuals with sickle cell trait (hemoglobin $\mathrm{S}+\mathrm{A}$ ), in the membrane hemoglobin prepared from $\mathrm{S}-\mathrm{C}$ individuals, hemoglobin $\mathrm{S}$ accounted for only 28 per cent of the pigment. Ponder (14) summarized evidence that erythrocyte membranes contain strong acid 
groups; the more electropositive hemoglobin components might thus be found in greater concentration in the membrane pigment.

Kaplan, Zuelzer and Neel (15) first observed that the principal morphologic abnormality associated with presence of hemoglobin $C$ was the increased number of target cells on blood smears. The large amounts of hemoglobin $\mathrm{C}$ which were found in the erythrocyte membranes of individuals with sickle cell-hemoglobin C disease, or hemoglobin $C$ trait may be related to the formation of target cells. A similar relationship between the sickling phenomenon and the presence of hemoglobin $\mathrm{S}$ in erythrocyte membranes was postulated by Anderson and Turner (1).

Target cells and microcytosis are frequently observed on blood smears of individuals with thalassemia minor. Electrophoretic analyses of the membrane hemoglobin of four individuals with thalassemia minor disclosed an increased amount of hemoglobin $A_{2}$ in the membrane pigment ; however, the relative increase in hemoglobin $A_{2}$ in the red cell membranes of these individuals was not significantly different from the increases observed in normal erythrocyte membranes.

\section{SUMMARY}

1. Electrophoretic analyses of the hemoglobin associated with erythrocyte membranes disclosed the presence of the three known hemoglobin components $\left(A_{1}, A_{2}\right.$ and $\left.A_{3}\right)$ in normal membranes. A larger proportion of hemoglobin $A_{2}$ was found in the membrane pigment than in water-soluble hemoglobin.

2. The membrane hemoglobin of individuals with sickle cell trait or hemoglobin $C$ trait contained a larger proportion of the abnormal hemoglobin than did the water-soluble or hemolysate hemoglobin. The membrane hemoglobin of patients with sickle cell-hemoglobin $\mathrm{C}$ disease contained relatively larger amounts of hemoglobin $\mathrm{C}$ than did the water-soluble hemoglobin. While an increased proportion of hemoglobin $\mathrm{A}_{2}$ was observed in the membrane pigment of individuals with thalassemia minor, the increase was within the range observed in membrane hemoglobin prepared from normal erythrocytes.

3 . The results were consistent with the hypothesis that the binding of hemoglobin to the erythrocyte membrane is related to the hemoglobin charge, but other possible explanations for the observations were discussed.

\section{ACKNOWLEDGMENT}

The authors wish to express their appreciation to Dr. Joseph C. Turner for his helpful advice, and to Dr. G. Marlowe Smith and Mr. Alan S. Jacobs for assistance with many of the analyses.

\section{REFERENCES}

1. Anderson, H. M., and Turner, J. C. Preparation and the haemoglobin content of red cell "ghosts." Nature (Lond.) 1959, 183, 112.

2. Anderson, H. M., and Turner, J. C. Relation of hemoglobin to the red cell membrane. J. clin. Invest. $1960,39,1$.

3. Drabkin, D. L. Spectrophotometric studies. XIV. The crystallographic and optical properties of the hemoglobin of man in comparison with those of other species. J. biol. Chem. 1946, 164, 703.

4. Crosby, W. H., Munn, J. I., and Furth, F. W. Standardizing a method for clinical hemoglobinometry. U. S. armed Forces med. J. 1954, 5, 693.

5. Kunkel, H. G., Ceppellini, R., Müller-Eberhard, U., and Wolf, J. Observations on the minor basic hemoglobin component in the blood of normal individuals and patients with thalassemia. J. clin. Invest. 1957, 36, 1615.

6. Smithies, O. An improved procedure for starch-gel electrophoresis: Further variations in the serum proteins of normal individuals. Biochem. J. 1959, $71,585$.

7. Kunkel, H. G., and Bearn, A. G. Minor hemoglobin components of normal human blood. Fed. Proc. 1957, 16, 760.

8. Wells, I. C., and Itano, H. A. Ratio of sickle-cell anemia hemoglobin to normal hemoglobin in sicklemics. J. biol. Chem. 1951, 188, 65.

9. Neel, J. V., Wells, I. C., and Itano, H. A. Familial differences in the proportion of abnormal hemoglobin present in the sickle cell trait. J. clin. Invest. $1951,30,1120$.

10. Kunkel, H. G., and Wallenius, G. New hemoglobin in normal adult blood. Science 1955, 122, 288.

11. Hasserodt, U., and Vinograd, J. Dissociation of human carbonmonoxyhemoglobin at high $\mathrm{pH}$. Proc. nat. Acad. Sci. (Wash.) 1959, 45, 12.

12. Singer, S. J., and Itano, H. A. On the asymmetrical dissociation of human hemoglobin. Proc. nat. Acad. Sci. (Wash.) 1959, 45, 174.

13. Allison, A. C. Observations on the sickling phenomenon and on the distribution of different haemoglobin types in erythrocyte populations. Clin. Sci. 1956, 15, 497.

14. Ponder, E. Hemolysis and Related Phenomena. New York, Grune and Stratton, 1948, pp. 134-135.

15. Kaplan, E., Zuelzer, W. W., and Neel, J. V. A new inherited abnormality of hemoglobin and its interaction with sickle cell hemoglobin. Blood 1951, 6, 1240. 